\title{
Virtuality, Architecture, and the Question of Control
}

\author{
CARLOS H. BETANCOURTH \\ Columbia University \\ USA
}

\begin{abstract}
I would discuss Electronic Environments inrelation to the theme of the Conferen-ce, namely, "Defining The Urban Condition: Accelerating Change in The Geography of Power". In so doing, I will refer this discussion to design and architecture. In order to do this, I will look at the implications of Virtuality and Virtual Spaces for organizations in which Information, is the main raw-material of work. Since design maybe one of these organizations, I hope this will be of relevance to design organizations. I will read the implications of virtuality for such organizations by looking at the structure of virtual space. Next, I will deal with the implications of virtuality for both, the concept of space and architecture. I will then derive the main limitations of virtuality from its effects on space. I will also try to see how these consequences of virtuality on space and architecture may cause us to re-think what we mean by an 0rganization. I will then suggest ways by means of which "electronic environments" can help us to overcome the limitations of virtuality. I will end with some comments on some of the main limitations of this electronic environments.
\end{abstract}

\section{THE STRUCTURE OF VIRTUALITY}

Let's briefly look at the structure of the worldwide computer network known as the "internet." Unlike telephone calls or fax transmissions, which link specific machines at identifiable locations, an exchange of electronic mail links people at indeterminate locations (Mitchell, 1993; Betancourth, 1994a). What this means is then that people involved in virtual exchanges operate on their own, out of no common place - out of sight and perhaps out of touch but on line.

\section{THE CONSEQUENCES OF VIRTUALITY}

By linking people at indeterminate locations, virtual interactions and exchanges in virtual space (video-conferencing, portable telephone, e-mail) de-spatialize interactions. In so doing, they eliminate a dimension of social legibility traditionally provided by spatial cities and their buildings: contrary to what occurs in a spatial city and in a building in which where you are frequently tells who you are, in a virtual exchange there is no such a thing as a better address, and you cannot attempt to define yourself by being seen in the right places in the right company.It may then follow from here that for economic organizations, whose lifeblood is information, virtuality means that work is what you do, not where you go. And this maynot be without serious consequences for such economic organizations.

But, before moving into this, let us first, notice in passing that the struc-ture of virtuality isn't without serious implications for the concept of space: From the point of view of social theory, space is the material support and articulation of practices that are simultaneous in time. Space brings together in physical contiguity practices thar are simultaneous in time. This then means that the notion of space is assimilated to contiguity.But, virtual-ity introduces the possibility of practices that are simultaneous in time, that don't necessarily rely on physical contiguity. Which is to say that if we are going to account for the existence of material supports of simultaneity that don't rely on physical contiguity, we would have at least to separate the concept of material support from the notion of contiguity (Due to space limit-ations we would not go into this now).

Virtuality (and globalization) offers to Organizations where information is the raw material of work, the challange of the idea of an activity without a building as its home. Let us now try to imagine the idea of an organization whose lifeblood is information, as a concept; not as a place; as an activity, not as a building.

\section{AN ORGANIZATION AS A CONCEPT RATHER THAN AS A PLACE}

The participants in such virtual organization, will communicate from wherever they happen to be, via e-mail, mobile phone and video-conferencing. As result of this, it is not necessary for this organization to have all the same people in the same place at the same time. With virtualization it then becomes possible for more work to be done outside the traditional office (NYT, June 25, 1995). Which means that if such an organization was say, a library, a University, or an 
accounting firm, it would have to consider replacing the grand building with a network of tiny libraries in every town through a region, each linked to a central facility and, to every library in the world if need be.

It can then be suggested that these virtual-exchanges inagurate a "new logic of industrial location." Castells, Scott and others (1988) have already referred to this locational strategy as the "new industrial space." Since this space is characterized by the technological and organizational ability to separate the production process in different locations while reintegrating its unity through telecommunications linkages, and micro-electronics based precision in the fabrication of components, we could also refer to this space, as a "new industrial virtual space." But as libraries and international companies disperse their operations, as they set up factories, service outlets, subsidiaries, affiliates, subcontractors, etc, overseas, what are the sort of questions and dilemmas they are faced with? That is, if tele-technology makes possible a new kind of organization, what are the main characteristics of such organization? And which are the main barriers to such organization and its form? I would like to propose to deal with this question by briefly looking at the architectural consequences of virtuality.

\section{VIRTUAL ORGANIZATIONS}

Several writers ( Baden-Fuller 1992; Hampden-Turner 1990; and, Handy, 1989; 1994; 1995), have argued that when intelligence is the primary "intangible, inexhaustible" asset of an organization, the idea of virtuality implies that large part of organizations will be made up of ad hoc miniorganizations. The organization becomes more like a collection of project groups. These projects groups are collated for a particular time and purpose, drawing their participants from both inside and outside the parent organization. Some of these project groups maybe permanent, some temporary, and some in alliance with other parties. Such organizations, instead of adding functions, substract or subcontract them. They may constitute networks of production and management, whose flexibility needs not to internalize workers and suppliers, but to be able to access them when it fits, and in the time and quantities that are required in each instance. This flexibility then means that project groups in such organizations and virtual exchanges, maybe then activities rather than buildings. Thus, instead of being a castle, a home for life for its defenders, a virtual organization will be more like an apartment block, an asso-ciation of temporary residents gathered together for mutual convinience.The apartment block may in fact, not have a physical existence, because the project groups or clusters don't have to be in the same place or even employed by the same organization. Some companies are no more than temporary project groups, put together from various sources with a specific task to do, meeting mostly by video conferences, e-mail and voice mail. Such "virtual organization" may be discerned more easily on the computer screen than in the physical world. Carried to its limits, such a company is hollowed out, its staff reduced to a minimum, its activities carried out at dispersed locations, the organization itself becoming what Handy has called an "unseen organization" as a "nexus of contracts." At this point one shoud ask and wonder about whether a company is, in the future, going to be anything more than a "box of contracts." Is a "box of contracts" a sustainable basis for efficiency and control, or is it a recipe for disintegration? What will hold such an organization back from becoming such a "box of contracts?" Such a dispersal and disintegration of economic activity also mean that companies run into questions of maintaining centralized control. Moreover, as a "box of contracts," a virtual organization search for wealth might have destroyed wealth and split society in two. The challange is then to control an organization that is not there in any sense in which we are used to. How can management hold the virtual corporation together? How can this challange be met, is a question I would like to deal with next, by looking at the spatial and architectural consequences of virtuality.

\section{THE SPACE OF THE VIRTUAL ORGANIZATION}

How is then this flexibility and adaptability of the virtual organization, better served? Professor Sassen suggested in her opening speech (But see also Sassen, 1991; 1994) that this flexibility and adaptability is better served by a combination between agglomerations of core networks and global networking of these cores, and their dispersed, supplementary networks, via telecommunications and air transportation (For an study on the limitations of a similar "planning concept," see Betancourth, 1993). Sassen also suggested that such networks contribute to strengthen the concentration of high level activities in a few nodes. Moreover, since dispersal of economic activity overseas means that international companies run into questions of maintaining centralized control, the capacity for global dispersal itself raises the importance of central control functions in agglomerated locations (Sassen, op.cit). Yet, these advanced services activities also seem to disperse and decentralize to the periphery of metropolitan areas, to smaller metropolitan areas, to less developed regions, and to some less developed countries (for evidence on spatial decentralization of services, see Castells, 1989; Daniels, 1993; Marshall et al, 1988; M. Dunford and G. Kafkalas, 1992). It may then follow from this that what maybe significant about this spatial system of advanced services activities maybe neither concentration or decentralization, since both processes seem to be taking place at the same time throughout countries and continents. What matters the most may then be the versatility of the networks of this spatial system. Which is to say that the "Global city" may not be a place but a process.

\section{THE ARCHITECTURE OF VIRTUALITY}

This versatility of the networks may in turn imply that the projects groups of the above ad hoc miniorganizations maynot have one place to call their own: Organizations 
collapse and disperse their centers; they spread their center around. There is no need to have all the people with responsibilities across the organization sitting in the same central place. Project groups may exist as activities not as buildings, their only visible sign is an e-mail address. Inside the building that do exist, hot-desking maybe increasingly common. In international business video-conferencing maybe the norm. Trains may double as mobile offices, with the commuter's doze interrupted by the ringing of personal phones and the bleeping of portable computers. And if virtual exchanges mean that we will be able to call anyone without knowing where they are or what they are doing, the office as the home of the telephone and of the computer - with a secretary to answer it and a line plugged into the wall - will become an antiquated and very expensive notion that organizations can ill afford. But, the formation of virtual business networks and the trend toward the disaggregation of labor above, doesn't imply the end of the office, but the diversification of working sites for a large fraction of the population; its professional segment. Increasingly mobile telecomputing equipment will then enhance this trend towards the officeon-the-run (Business Week, 1994). Power doesn't need to be concentrated in one place. The center can now be well informed but small, it can be strong but dispersed. The nerve center of the organization can be in the chief executive's laptop computer-and seve-ral others simultaneously. This new, dispersed center has still, however, got to talk to itself as well as contemplete its screens. Video-conferences, voice mail, e-mail and other technological devices help, but there may not be a real substitute for looking someone in the eye while you talk or they talk. Dispersed centers also mean a lot of travel and red-eyes. These low-bandwith connections cannot fully substitute for face to face contact. And, assuming that higher-bandwith connections and telepresence (when you are able to initiate a business conversation by shaking hands at a distance), are not yet able to make machinemediated conversation and companionship seem better bargains than face-to-face, it could be suggested that the physical centers of these dispersed virtual organizations, increasingly begin to resemble clubhouses (or even Hotels, as in the case of companies like the Ernst \& Young accounting firm, NYT, op.cit). Thus, if there is an office in the future, it will be more like a club house: a place, not for doing daily work, but, for meeting, eating and greeting, with rooms reserved for activities, not for particular people.

At this point one may have to begin to wonder what will happen to the cathedrals of corporate power, the towering blocks which shape our skylines. And indeed, if those in the center are not all-seeing, we may find them coming physically closer to the ground. A changing skyline may then be the outward sign of "subsidiarity" and "virtuality." Thus, not only companies like Ernst \& Young accounting firm run many of their offices just like hotels, allowing employees to check in only temporarily, but the tallest building at Microsoft's headquarters near Seattle soars three stories (NYT, op.cit). There are some serious implications for architecture already at work here: The virtualization of space tends to blur the meaningful relationship that previously existed between architecture and society. Because action takes place at a distance, in virtual space, around the world, and across cultures, virtuality not only tends to uproot experience, history and specific cultures as the background of meaning, but it may lead to the generalization of a ahistorical, a-cultural architecture. The "ideological mission" of architecture tends to disappear. There is not any need now to express the value of Western capital in architecture. Corporate America doesn't need to "express" itself in buildings (NYT, op.cit). And the media, anyway, may provide them, that identity much better. Thus, from the Gothic cathedrals to today's architecture and by way of virtualization (print, radio, TV, film, video, etc), architecture may have lost its symbolic condition as a strong media. All these above bring us in touch with the limitations of virtuality. These limitations maybe of two kinds: they relate to the loss of a sense of place and to the loss of a sense of control.

\section{THE LOSS OF A SENSE OF PLACE}

Information substitutes for high-cost inventory. By speeding the responsiveness of the factory to the market and making short runs economical, better and more instantaneous information makes it possible to reduce the amount of components and finished goods sitting in warehouses or railroad sidings. Just-in-time delivery of parts, based on computerized information, seems to be slashing inventories everywhere. These cuts in inventory, not only translate back into smaller space and real estate costs, but also into reduced taxes, insu-rance and overhead. And even though the initial cost of computers, software, information and tele-communications may itself be high, this savings in space and real estate costs, mean that a company needs less capital to do the same job it did in the past (See also, NYT, op.cit). Add to this the possibilities that the World Wide Web offer as a medium on which to practice new conventions of advertising: when a company goes onto the web, it has no need to take space from a media-owner. It may hire computer space from an Internet provider, but it can set up its own server in-house which allows access to anyone on the Net. And even though, there are on-line newspapers and magazines in which companies can place advertisements, there is not need to use these either. Thus, the monopoly which media-owners had on advertising space for so many years in the real world, maybe shattered in cyber-space and virtuality. And since advertisers in the net cannot guarantee consumers will come across commercial messages in the same way as they do in print, radio or TV, internet advertising sites will have to serve as shop windows from which you can buy something. The development and adoption of computer security technology will in turn, enable you to click a line on your screen and your credit card number will be transmitted to the company and its product will be with you in the post. Already there are florists, booksellers, record shops and clothing manufactur- 
ers offering this service (Canter, 1995). Again, this suggests the breakdown of traditional commercial structures. Just as companies are being allowed to bypass media-owners, so they can now bypass retailers. As a result of all this above, and, relatively speaking, information seems to reduce the need for capital per unit of output in a given economy.Computerized equipment not only substitutes for human labor but also for capital. Thus, by saving space and real estate costs, as well as media and retail space, information maybe a threat to the power of finance, media owners and retailers. At a more specific level, the virtual office (e.g., the mobile office and the office as a clubhouse) above may also be a threat to the executive, for whom a room of his own, or at least, a desk of his own, has been his security blanket for a century or more. For such an executive, a sense of place and a sense of purpose are still very important. E-mail and voice mail and the immediacy they are able to provide, aren't for this executive, the same as watching the eyes of others. It may then be expected that few executives are going to be eager advocates of virtuality when virtuality means that work is what you do, not where you go. What happens when information starts to reduce the need for capital as well as to eliminate a sense of place and of purpose? Moreover, information - the raw material of the virtual organization - is a slippery, intangible and inexhaustible asset capable of being used by many people that - and as distinguished from land and factories - isn't easy to fence off and defend. And whether those intangible assets are the research in a company's pipeline, the brands, the know-how, or the networks of experience, they amount in the end to one thing: the people. Those people can and often do walk out of the door. The assets of the new information-based organizations are, as resut, increasingly fragile. Information is then a raw material that cannot be easily "owned." Given all these consequences of virtuality on space, executives and property, nor only is the virtual organization a difficult thing to hold together, but, a conflict may then emerge between those controlling an industrial society, and those wanting to replace it with a network society. One should then expect that some sort of resistence to virtualization may emerge from all this. And since what seems to be at the bases of this resistence is a loss of a sense of place, the question then becomes: How and for what can we substitute this sense of place? The challange is then to manage an organization that is not there in any sense in which we are used to. The question is then how to hold the virtual organization together? To meet this challange and to deal with this question above maybe important and urgent, because, whether we like it or not, the mixture of globalization and tele-technology means that more and more people will be spending time in, partly unseen virtual organizations and spaces - out of sight if not out of touch. For managers this may imply that no longer will their colleagues be down the corridor, available for an unscheduled meeting or a quick progress check. Most meetings will have to be scheduled, even those on video, and will therefore become more infrequent. Managers will have to learn how to run organizations without meetings and "without corridors" (On the effects of information for the architecture of an organization, see Betancourth, 1988, 1992). But most important: managers will have to get accustomed to working with and managing those whom they don't see, except on rare and prearranged occasions. And this maybe harder than it sounds. Thus, the problem faced by organizations here, isn't only one of how to "maintain centralized control" (Sassen, op.cit) in conditions of virtuality, but of how the implications of virtuality on space and control above, may require to rethink this very same old notions of control. A problem here is then how does a manager work and manage those whom she doesn't see, when the condition for control is precisely to be able to see them?

\section{THE LOSS OF A SENSE OF CONTROL}

Now if to work with and manage those whom managers don't see is a difficult task, it is mainly because managers don't want their employees to do their work where it suits them, and then send it down the wire. And this as result of the fact that managers want their employees where they can see them. Thus, editors, sitting down a long room behind large plateglass windows, like to be able to see what everyone is doing, to check the work, or to interrupt it whenever they need to give out a new assignment. Which means that managers don't trust their employees. As result, organizations are then arranged on the assumption that people cannot be trusted or relied on, even in tiny matters. Oversight systems similar to those described by $M$. Foucault are set up to prevent anyone from doing the wrong thing, whether by accident or design (Betancourth, 1988). An organization as a system of checkers, and of checkers checking checkers exists because managers no longer trust people to act for anything but their own short-term interests. An organization arranged on the bases of control and of lack of trust, may become a barrier to virtualization.

It may follow from this above that, virtuality requires trust to make it work. But, the nature of ownership and control, that is, the so-called "social relations of production" seems to prevent the further development of the "means of production," of virtualization. Yet, organizations in which information is the raw material of work may be exposed to a constant pressure to virtualize. The question then becomes: How can you run an organization based on trust rather than control? What are the rules of trust? And whatever the rules of trust maybe, how can they be embodied in virtual exchanges? What are the implications of this virtual requirement for trust, for a concept of 'centrality' grounded on the notion of control? It may then follow from this above, that if we are to take advantage of the virtual organization, we will have to substitute a sense of place for a sense of community, and, to rediscover how to run organizations based more on trust than on control, since virtuality requires trust to make it work. In what follows next we will briefly deal with the "principles of trust" and how these principles can be embedded in virtual space. 


\section{THE PRINCIPLES OF TRUST}

Due to space limitations, let me summarize them as follows (But, see Handy; op.cit; as well as Winograd, 1986; and, Rorty, 1979, 1991): What maybe important about the principles of trust, is that, an organization based on trust rather than on control may be an organization of collegues, peers and friends (some sort of "Agora." Betancourth, 1994a). For such an organization to have any chance of success, in a situation in which action is action at a distance, its members would have to know each other very well, have total confidence to do their jobs and a shared commitment - almost a passion - for the same goal. But, a shared commitment still requires belonging and touch. The combination of work and play as it occurs in corporate conference resorts (theme parks) could provide this sense of belonging to a community. Such conference resorts may become lubricants of virtuality: occassions not only for getting to know each other but also for reinforcing corporate goals and rethinking corporate strategies. Thus, a way to avoid disintegration and a way to gel the goals of small units with the goals of the larger group is through bonding, touch and community. Notice that since the main limitations to virtuality were the loss of a sense of place what the principles of trust propose in order to overcome these barriers is to replace a sense of place by a sense of community. What the principles of trust are suggesting is then that an organization conceived as a community understood as a network of small units or families, is the organizational form needed for controlling a virtual organization. But, before moving into the limitations of this approach, let us see how these principles can be translated into "electronic environments." How is the concept of a company, meaning a fellowship, a group of companions, a clubhouse, retranslated into an electronic environment? This may imply to create communities that one can describe but that don't necessarily belong to any place. How are these virtual villages and cities created?

\section{ELECTRONIC ENVIRONMENTS}

Today, the term "Cyberspace" seems to denote the world of current electronic networks which users are said to experience as a surfers' paradise, a great good place of infinitely pleasurable anarchy. The myth of freedom on the superhighway is a commonplace of contemporary media comment (Negroponte, 1995; Gilder, 1995). Yet, the idea of networks as common ground without boundaries, fences or "no entry" doesn't seem to mix well with the principles of trust required by the virtual organization. These principles require specialized software and a secret password to $\log$ on in the first place. Secret passwords, subscription accounts, credit card numbers, "Aliases" and "software surrogates," are all attempts to construct an "electronic identity" (Mitchell, 1993; Betancourth 1994a). Secret passwords then embody principles of trust required by a virtual organization: they maybe able to guarantee an organizational architecture made up of constant groupings. Moreover, surrounding information, with copyright, electronic passwords and codes maybe a way to 'own' this slippery, intangible, inexhaustible substance capable of being used by many people at once. In a sense, these passwords are ways to fence off and defend that on which, wealth and power maybe based, namely, the property of information ( Cavazos 1995). Thus instead of the freedoms currently claimed by internet users what we seem to have is also a growing culture of cyberspace regulation, which is designed to counter the perceived ability of hackers, virus bombers, software pirates (e.g., the recent Chinese software piracy), and computer pornographers to subvert the new world order (On The communication decency act, see Bennahum, 1995).

\section{THE NET RECONCEIVED AS A CYBERCITY/ELECTRONIC AGORA}

\section{The Rights Industry, and The Question of Control}

The myth that cyberspace cannot be policed reflects the perception that up to know it has not needed policing. The requirements of the virtual organization may change all this. And indeed, as spatial cities, that aren't only condensations of activity that maximize accessibility and promote interaction, the net can also be designed as such cities, that is, as a (non-architectural) structure for organizing and controlling access and owning information: in the net, you enter and exit places by establishing and breaking logical linkages, not by physical travel. Thus, the architect and the planner of the net as such structure of access and exclusions, is then, the rights industry: The rights industry also subdivides the net into districts, neighborhoods, and turfs, legally partitioned by property lines and jurisdictional boundaries, and segmented into nested enclosures by fences and walls. It is in this sense that one may talk of the net as a "Cybercity" and as an "Electronic Agora" (Mitchell, op.cit). Such cybercities and electronic Agoras could then provide that form of belonging and touch, of community and extended family, required by the virtual organization. Now, even it is very important to look at the implications for the culture of the networks of this redesign of the net as a "cybercity" of access and exclusions, attention would have to be given to the following: that even if you surround, fence off and defend information with "fences and walls" that is, with a "cybercity" of electronic passwords and codes, sooner or later some hacker, some software pirate, will come along and set information loose just for fun (which brings us back to the problem of a conflict between those who would keep information frozen as property and those who would let it free). Thus, passwords, software agents and electronic agoras may not be enough to fence off and defend "cyberproperties" and "cybercommunities." Hackers, virus bombers, software pirates and computer pornographers are always able to overcome these "cyberwalls" and "cyberfences." We may then still need to wait for telepresence to guarantee the "policing" job (On this See Mitchell and Betancourth, op.cit). Telepresence in the context of a virtual organization could 
provide those forms of bonding and of touch required for a virtual organization to be able to work. And this sense of belonging to a community could in fact substitute for the loss of a sense of belonging to a place, which was defined above, as one of the main barriers to the virtual organization. The virtual community as a network of families may then be a way to control the virtual organization. But the question remain as to the implications of these virtual communities.

\section{THE LIMITS OF THE VIRTUAL COMMUNITY AS A NETWORK OF FAMILIES}

The principles of trust and electronic environments, aim at reducing manager's fear of lossing control in conditions of virtuality, by replacing a sense of place for a sense of community, and a sense of control by a sense of trust. In so doing they may in fact, reduce the barriers to virtualization. But, at the same time, they also introduce some sort of "electronic agorophobia," that is, the fear of open space and masses of people; the fear of exchange, of discussion and of contact with the multiple (Betancourth, 1994a). And this may not be without implications for the culture of the networks, when the later is understood as a common ground without boundaries or "no-entry," that is, as the most interactive and democratic communication medium that has ever existed (Garry, 1995). Indeed, one could understand the "cybercity" as the expression of the power of the rights industry to mould the net in its own image. But, we also feel that these virtual communities and extended families need to be questioned mainly because of the implications of this principles of trust for the management and organization of Highly Differentiated Societies. To develop this critique implies to look at the problem of the production of information. Briefly stated this critique may be as follows:

\section{The production of Information}

Information implies inquiry and inquiry requires obervation and perception. The only source of new information is the as yet uncoded, the random and unpatterned, the "noise" of the outside. To create information requires observation, that is, the use of distinctions in order to be able to designate something, that is, in order to distinguish figure from ground, "X" from "non-x." This then implies that all observations are produced by a contingent ob-server who could always describe things otherwise. Hence, all observations and all systems described by them contain an irreducible element of complexity: contingency - the ability to alter perspectives, acts as a reservoir of complexity within all simplicity. This is then the main point that seems to be missing from at least, Handy's account of the "principles of trust," "extended families," and "communities," as well as from Mitchell's account of "electronic environments," "agoras," and "virtual communties": what these accounts have in common is the hope to reduce this complexity, via social consensus, the identity principle, and the ideal of undistorted communication. But if all observation is made possible by a distinction to which it must remain blind, a consensual integration such as that implicit in the principles of trust, of electronic agoras, and, of cybercities, can only result on the paradoxes of observation becoming invisible to all and remaining that way for an indefinite future (Luhmann, 1989; Betancourth, 1994a). Which is to say, that the recontainment of contingency via cybercommunities, cyberfamilies and electronic agoras is a project that may result in the blockage of communication.

\section{TO CONCLUDE}

If observation is constituted by a blind-spot, what maybe needed is not the exclusion of other oberving systems but a plurality of interlinked observing systems, exposing the blindspots of each other's positions. This may in turn enable a better functional performance of highly differentiated societies.

\section{REFERENCES}

Baden-Fuller, C, and J. Stopford. Rejuvenating the mature corporation, London: Routledge, 1992.

Bennahum, D. "Getting cybersmart," The New York Times, May 22, 1995.

Betancourth, C. "An study of The Transitorium Building," Unpublished working paper and designs, The Hague, 1988.

Betancourth, C. "Notes on the the change of address of The Ministry of Physical planning from a building with corridors to a building 'without' corridors," Unpublished working notes, The Hague, 1992.

Betancourth, C. "Het Tussenlandscahp," Een essay over de periferie als stedelijk centrum, RPD, VROM, The Hague, 1993.

Betancourth, C. "Cyberspace, or the forgetting of space"; unpublished paper, presented at a conference on Space, 14 Oct, Columbia University, New York; 1994.

Canter, L. and M. Siegel, How to make a fortune on the information superhighway, Harper Collins, 1995.

Castells M., "The New Industrial Space: information technology manufacturing and spatial structure in The United States," in G. Sternlieb and J. Hughes (eds) America's new market geography: Nation, region and metropolis, New Brunswick, NY: Rutgers University, 1988.

Cavazos, E., and G. Morin, Cyberspace and the law, Cambridge, MA: MIT Press, 1995.

Daniels, P. W., Informational society. An economic theory of discovery, invention and innovation, Boston/Dordrecht/London: Kluwer Academic Publishers, 1993.

Dunford, M., and G. Kafkalas (eds), Cities and regions in the Europe: the global local interplay and spatial development strategies, London: Belhaven Press, 1992.

Garry, P., Scrambling for protection, University of Pittsburgh Press, 1995.

Gilder, G., Life after television, Norton, 1995.

"The Great Asian Steeple Chase," New York Times, Week in Review, June 25, 1995.

Hampden-Tumer, C., Corporate culture. London:Hutchinson, 1990.

Handy, C., The age of unreason, Harvard Business School Press, Boston, Massachusetts, 1989.

Handy, C., The Age of Paradox, Harvard Business School Press, Boston, Massachusetts, 1994.

Handy, C., "Trust and the virtual organization," in Harvard Business Review, May-June 1995.

Luhmann, N., Ecological communication, Chicago: U of Chicago P, 1989. 
Marshall, J.N. et al., Services and uneven development, Oxford: Oxford University Press, 1988.

Mitchell, W., "The electronic agora," in "Electrotecture: architecture and the electronic future," $A N Y$, N3, Nov/Dec 1993.

Negroponte, N., Being Digital, Hodder and Stoughton, 1995.

"The new face of business," Business Week, Special issue on "The Info Revolution," 1994.

Rorty, R., Philosophy and the mirror of nature, Princeton: Princeton UP, 1979.
Rorty, R., "Objectivity, relativism and truth," Philosophical Papers, Vol. 1, Cambridge: Cambridge UP, 1991.

Scott, A., New Industrial Spaces, London, Pion, 1988.

Sassen, S., The Global City. New York, London, Tokyo, Princeton, NJ: Princeton Iniversity Press, 1991.

Sassen, S., "The new centrality: The impact of telematics and globalization," Dec 1994.

Winograd, T, and F. Flores, Understanding computers and cognition: $A$ new foundation for design, Norwood, NJ: Ablex, 1986. 